\title{
ANALISIS PENILAIAN DAN HARAPAN PASIEN POLI GIGI DAN MULUT DENGAN METODE SPIDER WEB BERDASARKAN DIMENSI MUTU DABHOLKAR
}

\author{
ANALYSIS OF ASSESSMENT AND EXPECTATION DENTAL POLYCLINIC'S PATIENTS WITH SPIDER WEB \\ METHOD BASED ON DABHOLKAR QUALITY DIMENSION
}

Mustika Dyah Permatasari, Setya Haksama

Fakultas Kesehatan Masyarakat, Universitas Airlangga, Surabaya

E-mail: mustikadyah@gmail.com

\begin{abstract}
There are many factors that determine health care service quality. One of them is the internal factor. This research was done to arrange recomendation increasingdental polyclinic utilization based on Dabholkar quality dimention. This was an observational study with cross sectional design of the 70 respondents who are representing dental polyclinic's patient in a month. Data were collected by questionnaires distributed to respondents to identify the respondent's assessment and expectation about physical aspects dimension, reliability dimension, personal interaction dimension, problem solving dimension, and policy dimension of dental polyclinic service quality. The conformity between assessment and expectation of respondentson service quality was analyzed based on Dabholkar quality dimension by using spider web. The results showed that most dimensions have been suitable about reliability dimension, personal interaction dimension and problem solving dimension. While the conformity of physical aspects dimension and policy dimension are not quite good. The conclusions showed that physical aspects dimension and policy dimension are the top priority, while reliability dimension, personal interaction dimension and problem solving dimensionneed repairement are still need to be maintained.
\end{abstract}

Keywords: Dabholkar quality dimension, physical aspects dimension, policy dimension

\section{PENDAHULUAN}

Penelitian tentang peranan penilaian (assessment) dan harapan (expectation) dalam interaksi pasien dengan jasa pelayanan kesehatan telah dilakukan sejak 30 tahun yang lalu Thompson dan Sunol (1995). Kedua ahli itu menekankan bahwa ideal expectation dalam arti "outcome yang lebih disukai oleh pasien" tergantung pada evaluasinya secara pribadi terhadap masalah yang sedang dihadapinya dan aktivitas untuk mencapai tujuan tersebut (pelayanan kesehatan).

Hasil penelitian Berry,et al (1993) menunjukkan bahwa terdapat sepuluh faktor utama yang mempengaruhi harapan pelanggan terhadap suatu jasa. Kesepuluh faktor tersebut antara lain, Enduring service intensifiers, berupa harapan yang disebabkan oleh orang lain dan filososfi pribadi seseorang mengenai suatu jasa; kebutuhan pribadi, meliputi kebutuhan fisik, sosial dan psikologis; transitory service intensifiers, terdiri atas situasi darurat yang membutuhkan jasa tertentu (seperti asuransi kesehatan dan asuransi kecelakaan) dan jasa terakhir yang pernah dikonsumsi pelanggan; persepsi pelanggan terhadap tingkat layanan perusahaan lain; self-perceived service role, yaitu persepsi pelanggan terhadap tingkat keterlibatannya dalam proses penyampaian jasa; faktor situasional yang berada diluar kendali penyedia jasa; janji layanan eksplisit, baik berupa iklan, personal selling, perjanjian maupun komunikasi dengan karyawan penyedia jasa; janji layanan implisit yang tercermin dari harga dan saran pendukung jasa; word-ofmouth, baik dari teman, keluarga, rekan kerja, pakar, maupun publikasi media massa; dan pengalaman masa lampau. 
Pemikiran awal penggunaan spider web untuk menganalisis kesesuaian penilaian dan harapan pasien dalam studi ini didasarkan bahwa sebenarnya spider web mampu menunjukkan seberapa besar ketidakmampuan seseorang atau kelompok dalam memenuhi kebutuhannya. Harapan dalam spider web digambarkan sebagai garis terluar yang menjadi standar. Sedangkan area antara garis penilaian dan harapan tersebut yang tergambar sebagai gap. Dengan begitu, peneliti dapat dengan mudah menunjukkan ketidaksesuaian antara penilaian dan harapan pasien.

Teori mengenai service quality salah satunya adalah teori dimensi mutu Dabholkar. Dabholkar mengubah konsep yang tradisional seperti Reliability, Assurance, Tangible, emphaty dan Responsiveness (RATER), Service Quality (SERVQUAL), dan Perceived Service Quality (SERPERF) menjadi konsep yang baru meliputi limadimensi utama. Peneliti menggunakan lima dimensi tersebut sebagai alat untuk menilai mutu .pelayanan kesehatan sebab dimensi mutu pelayanan Dabhlokar, et al (1996) mampu menjelaskan secara akurat persepsi pelanggan terhadap kualitas jasa.

Jumlah kunjungan pasien pada poli gigi dan mulut mengalami sejumlah kenaikan dan penurunan dari tahun 2010-2013. Pasien di Poli Gigi dan Mulut mengalami peningkatan jumlah kunjungan pasien pada tahun 2010 - 2012. Namun terjadi penurunan jumlah kunjungan pasien pada tahun 2013. Terjadi penurunan tren yang sangat tajam yakni mencapai 382 pasien dengan penurunan tren sebesar $11,41 \%$ pada tahun 2013. Padahal jumlah kunjungan pasien cenderung terus meningkat dari tahun 2010-2012.

Penelitian ini bertujuan untuk menganalisis penilaian dan harapan pasien di Poli Gigi dan Mulut berdasarkan kajian dimensi mutu Dabholkar.Hasil dari penelitian ini diharapkan dapat digunakan sebagai rekomendasi untuk perbaikan mutu pelayanan di Poli Gigi dan Mulut.

\section{PUSTAKA}

Dabholkar et al (1996)mengembangkan suatu model kualitas jasa yang dievaluasi pada tiga level berbeda, yakni level dimensi, level keseluruhan (overall), dan level subdimensi. Pelayanan yang diberikan melibatkan hubungan antara pasien dan pegawai selama pasien berada di rumah sakit. Dimensi mutu Dabholkar memiliki lima dimensi utama yang mempengaruhi mutu pelayanan pada suatu pelayanan kesehatan. Kelima dimensi tersebut adalah dimensi aspek fisik, dimensi reliabilitas, dimensi interaksi personal, dimensi pemecahan masalah dan dimensi kebijakan.

Dimensi aspek fisik (Physical aspects) meliputi penampilan fasilitas fisik (Physical Appereance) dan kenyamanan yang ditawarkan kepada pelanggan berkaitan dengan layout fasilitas fisik (layout convenience). Dalam penelitiannya, Dabholkar et al (1996), menemukan bahwa pelanggan mengamati kebersihan, penampilan umum dan fasilitas umumnya. Dalam penelitian ini, penilaian dan harapan responden mengenai dimensi aspek fisik terdiri dari beberapa variabel, antara lain jumlah sumber daya manusia (SDM), jumlah fasilitas penunjang medik, kelengkapan fasilitas penunjang medik dan kondisi ruangan poli gigi dan mulut. 
Dimensi reliabilitas (reliability) memiliki dua faktor utama yang nantinya akan dikembangkan menjadi beberapa variabel dalam penelitian ini. Dua faktor utama yang harus muncul dalam dimensi reliabilitas adalah memenuhi janji pada pasien sesuai yang dijanjikan (fulfilling promise) dan memberikan pelayanan yang tepat (doing it right). Dalam penelitian ini, penilaian dan harapan responden mengenai dimensi reliabilitas terdiri dari beberapa variabel, antara lain konsistensi jadwal pelayanan, konsistensi jam pelayanan, lama waktu tunggu, dan keterampilan dokter, perawat dan petugas medis dalam melayani pasien.

Dimensi interaksi personal (personal interaction)mengacu pada kemampuan pegawai pemberi jasa dalam menumbuhkan kepercayaan pada pasien (Inspiring confidence) dan sikap sopan atau suka membantu (Courteousness or helpfulnes) (Dabholkar, et al, 1996). Dalam penelitian ini, penilaian dan harapan responden mengenai dimensi interaksi personal terdiri dari beberapa variabel, antara lain keterampilan berkomunikasi dokter dan perawat kepada pasien, sikap dalam menyampaikan informasi oleh dokter dan perawat kepada pasien, kejelasan informasi yang diberikan kepada pasien, gaya bahasa yang digunakan oleh dokter dan perawat kepada pasien dan cara penyampaian informasi.

Dimensi pemecahan masalah (problem solving) adalah dimensi yang membedakan antara model SERVQUAL yang dikembangkan oleh Parasuraman dengan model kualitas jasa yang dikembangkan Dabholkar et al. Dimensi ini berkaitan dengan kepekaan tenaga rumah sakit dalam menghadapi perubahan selalu memberikan perhatian dalam menyelesaikan komplain dari pasien dan keluarganya. Dalam penelitian ini, penilaian dan harapan responden mengenai dimensi pemecahan masalah terdiri dari beberapa variabel, antara lain faktor penyulit, gangguan teknis dan gangguan non teknis.

Dimensi kebijakan(policy)mempengaruhi berbagai aspek di dalam kualitas jasa sebab dimensi ini memperkuat aspek-aspek yang secara langsung dipengaruhi oleh kebijakan rumah sakit.Dalam penelitian ini, penilaian dan harapan responden mengenai dimensi kebijakan terdiri dari beberapa variabel, antara lain standar operasional prosedur (SOP), tata tertib, hak dan kewajiban pasien serta hak dan kewajiban petugas.

Salah satu faktor psikologis yang mempengaruhi pembeli adalah penilaian. Penilaian merupakan suatu proses yang timbul akibat adanya rangsangan yang diterima melalui panca indera sehingga seseorang dapat menyimpulkan informasi dan menafsirkan pesan dan hal ini dipengaruhi pula oleh pengalaman-pengalaman yang ada pada diri yang bersangkutan (Yohanna, 2009). Menurut Jacobalis, penilaian konsumen terhadap mutu pelayanan kesehatan dipengaruhi oleh beberapa faktor yang merupakan karakteristik dari pelaku penilaian antara lain umur, jenis kelamin, pekerjaan, tingkat pendidikan, sosial ekonomi, budaya, lingkungan fisik, serta kepribadian dan pengalaman pasien.Sesungguhnya persepsi dibentuk oleh tiga pengaruh, yakni karakteristik dari rangsangan eksternal dapat berbentuk fisik, visual atau komunikasi verbal yang mempengaruhi tanggapan 
individu, hubungan stimuli dengan lingkungan sekitarnya yang menyebabkan setiap orang dapat memiliki persepsi yang berbeda terhadap satu obyek yang sama dan kondisi yang ada dalam diri individu yang bersangkutan.

Penilaian pasien terhadap mutu pelayanan selain dipengaruhi oleh faktor - faktor yang telah disebutkan diatas juga dipengaruhi oleh harapan terhadap pelayanan yang diinginkan.Menurut Tjiptono (2004) faktor yang mempengaruhi harapan pelanggan adalah kebutuhan dan keinginan, pengalaman masa lalu, pengalaman teman-teman dan komunikasi melalui iklan dan pemasaran, faktor umur, pendidikan, jenis kelamin, kepribadian, suku, dan latar belakang budaya, serta kasus penyakit.Supriyanto (2003)mengatakan siapapun yang mengetahui secara khusus kebutuhan, keinginan atau harapan pelanggan maka dialah yang mempunyai keuntungan berhubungan dengan pelanggan.

Kepuasan berarti keinginan dan kebutuhan seseorang telah terpenuhi sama sekali. Kepuasan seorang penerima jasa layanan dapat tercapai apabila kebutuhan, keinginan, dan harapannya dapat dipenuhi melalui jasa atau produk yang dikonsumsinya.Kepuasan pasien bersifat subjektif berorientasi pada individu.Tjiptono (2004) juga menyebutkan bahwa kepuasan pelanggan memiliki hubungan yang erat dengan kualitas.Kualitas memberikan suatu dorongan kepada pelanggan untuk menjalin ikatan hubungan yang kuat dengan perusahaan.Dalam jangka panjang, ikatan seperti ini memungkinkan perusahaan untuk memahami dengan seksama harapan dan kebutuhan pelanggan. Dengan demikian perusahaan dapat meningkatkan kepuasan pelanggan dengan cara memaksimumkan pengalaman yang menyenangkan dan meminimumkan atau meniadakan pengalaman pelanggan yang kurang menyenangkan.Perusahaan juga dapat meningkatkan pangsa pasarnnya dengan memenuhi kualitas yang bersifat customer-driven. Hal ini akan memberikan keunggulan harga dan customer value. Customer value merupakan kombinasi dari manfaat dan pengorbanan yang terjadi apabila pelanggan menggunakan suatu barang atau jasa guna memenuhi kebutuhan tertentu. Bila kualitas yang dihasilkan superior dan pangsa pasar yang dimiliki besar, maka profitabilitasnya terjamin.Jadi, ada kaitan yang erat antara kualitas dan profitabilitas.

\section{METODE}

Penelitian ini merupakan penelitian
kuantitatif dengan metode penelitian observasional.Populasi dalam penelitian ini adalah pasien yang pernah datang untuk berobat jalan di Poli Gigi dan Mulut dalam satu bulan. Terkait saat pengambilan data, sampel dipilih menggunakan metode simple random samplingdengan jumlah populasi sebesar 248 pasien dengan probabilitas kunjungan customer ke pelayanan kesehatan sebesar $0,5(\alpha=0,1)$. Besar sampel pada penelitian ini adalah 70 responden.

Penelitian dilaksanakan selama bulan AprilMei 2015 di Poli Gigi dan Mulut.Teknik pengumpulan data menggunakanmetode wawancara kepada pasien, perawat dan dokter di Poli Gigi dan 
Mulut.Variabel dalam penelitian ini meliputi lima dimensi mutu Dabholkar.

Analisis data dilakukan terhadap setiap variabel penelitian dengan membuat tabel frekuensi.Hasil penilaian responden diberi skor 1 sampai 4 yang mewakili penilaian sangat buruk hingga sangat baik. Skornya yang sama juga digunakan untuk harapan responden. Setelah itu, dilakukan analisis tingkat kesesuaian antara penilaian dan harapan responden menggunakan spider web.

\section{HASIL DAN PEMBAHASAN}

Analisis Penilaian dan Harapan Responden di Poli Gigi dan Mulut Berdasarkan Dimensi Mutu Dabholkar

Berdasarkan hasil skoring penilaian dan harapan pada masing-masing dimensi mutu Dabholkar yang telah dilakukan sebelumnya, berikut merupakan hasil perhitungan rerata penilaian dan harapan responden di Poli Gigi dan Mulut berdasarkan dimensi mutu Dabholkar.

Pada dimensi reliabilitas, dimensi interaksi personal dan dimensi pemecahan masalah memiliki kesamaan hasil rerata penilaian dan harapan.Ketiga dimensi tersebut sama-sama memiliki penilaian yang sangat baik dan sangat diharapkan oleh responden. Dimensi pemecahan masalah hasil rerata penilaian dan harapannya kurang dari 1,75 akan tetapi masuk dalam kategori penilaian sangat baik dan sangat diharapkan oleh responden. Hal tersebut dikarenakan pada saat melakukan penelitian dimensi pemecahan masalah terdiri dari variabel yang menanyakan mengenai permasalahan yang mungkin terjadi sehingga semakin jarang permasalahan tersebut terjadi maka semakin kecil nilainya. Oleh sebab itu, khusus untuk dimensi pemecahan masalah semakin kecil rerata penilaian dan harapannya maka semakin baik penilaian dan harapan responden.

Dalam dimensi reliabilitas, dimensi interaksi personal dan dimensi pemecahan masalah dinilai baik oleh pasien dan sudah sesuai dengan harapan pasien.Seperti yang dikemukakan oleh Parasuraman et al (1998) bahwa kemauan untuk membantu pelanggan (pasien) dan menyediakan jasa pelayanan dengan cepat dan tepat, dikaitkan dengan kepuasan pelanggan.Jadi faktor ini perlu dipertahankan oleh pihak manajemen Poli Gigi dan Mulut karena kepuasan dan ketidakpuasan

Tabel 1 RerataPenilaiandan Harapan Responden di PoliGigi dan Mulut Berdasarkan Dimensi Mutu Dabholkar

\begin{tabular}{lrrrr}
\hline \multicolumn{1}{c}{ Dimensi } & Rerata Penilaian & Ket. & Rerata Harapan & Ket. \\
\hline Aspek Fisik & 2,47 & Buruk & 3,20 & Baik \\
\hline Reliabilitas & 3,36 & Sangat Baik & 3,30 & $\begin{array}{r}\text { Sangat } \\
\text { Diharapkan }\end{array}$ \\
\hline Interaksi Personal & 3,53 & Sangat Baik & 3,30 & $\begin{array}{r}\text { Sangat } \\
\text { Diharapkan }\end{array}$ \\
\hline Pemecahan Masalah & 1,61 & Sangat Baik & 1,70 & $\begin{array}{r}\text { Sangat } \\
\text { Diharapkan }\end{array}$ \\
\hline Kebijakan & 1,61 & Sangat Buruk & 3,42 & $\begin{array}{r}\text { Sangat } \\
\text { Diharapkan }\end{array}$ \\
\hline $\begin{array}{l}\text { Nilai Rerata Keseluruhan } \\
\text { Dimensi Mutu Dabholkar }\end{array}$ & 2,52 & Baik & 3,00 & Baik \\
\hline
\end{tabular}


konsumen terhadap suatu produk atau jasa akan mempengaruhi perilaku selanjutnya.

Dimensi aspek fisik dan dimensi kebijakan memiliki sedikit kemiripan dalam hal penilaian dan harapan responden. Responden menilai dimensi aspek fisik adalah dimensi yang buruk akan tetapi diharapkan dengan baik oleh responden. Sedangkan pada dimensi kebijakan, responden menilai bahwa dimensi kebijakan adalah dimensi yang sangat buruk akan tetapi sangat diharapkan oleh responden. Kemiripan yang terjadi antara kedua dimensi ini adalah adanya ketidak sesuaian penilaian dan harapan responden meskipun reratanya berbeda akan tetapi sama-sama tidak memenuhi harapan responden.

Poli Gigi dan Mulut harus menjadikan dimensi aspek fisik dan dimensi kebijakan sebagai prioritas utama.Dimensi aspek fisik dan dimensi kebijakan menjadi prioritas utama dalam upaya perbaikan dan peningkatan kualitas. Harapan pasien terhadap kedua dimensi tersebut baik bahkan sangat baik oleh sebab itu, hendaknya pihak Poli Gigi dan Mulut melakukan perbaikan pada kedua dimensi tersebut agar tercapai harapan pasien pada kedua dimensi tersebut.Terpenuhinya harapan pasien menyebabkan pasien memiliki kepuasan yang baik khususnya pada dimensi aspek fisik dan dimensi kebijakan.Meski demikian, ketiga dimensi lainnya juga tetap harus diperhatikan pemenuhan harapan pasiennya.

Tjiptono (2004) menyebutkan bahwa kepuasan pelanggan memiliki hubungan yang erat dengan kualitas. Kualitas akan memberikan suatu dorongan kepada pelanggan untuk menjalin ikatan hubungan yang kuat dengan penyelenggara produk / jasa.

Analisis Tingkat Kesesuaian Penilaian dan Harapan Responden di Poli Gigi dan Mulut Berdasarkan Dimensi Mutu Dabholkar

Berdasarkan hasil perhitungan rerata penilaian dan harapan pada masing-masing dimensi mutu Dabholkar yang telah dilakukan sebelumnya, berikut merupakan hasil analisis tingkat kesesuaian penilaian dan harapan responden di Poli Gigi dan Mulut berdasarkan dimensi mutu Dabholkar.

Tingkat kesesuaian penilaian dan harapan responden pada dimensi reliabilitas, dimensi interaksi personal dan dimensi pemecahan masalah adalah sangat sesuai. Kesesuaian antara penilaian

Tabel 2 Tingkat Kesesuaian Penilaian dan HarapanResponden di PoliGigi dan Mulut Berdasarkan Dimensi Mutu Dabholkar

\begin{tabular}{lrrrr}
\hline \multicolumn{1}{c}{ Dimensi } & Rerata Penilaian & Rerata Harapan & Tingkat Kesesuaian (\%) & Ket. \\
\hline Aspek Fisik & 2,47 & 3,20 & 77,20 & Belum Sesuai \\
\hline Reliabilitas & 3,36 & 3,30 & 102,00 & Sangat Sesuai \\
\hline Interaksi Personal & 3,53 & 3,30 & 106,97 & Sangat Sesuai \\
\hline Pemecahan Masalah & 1,61 & 1,70 & 94,71 & Sangat Sesuai \\
\hline Kebijakan & 1,61 & 3,42 & 47,10 & Belum Sesuai \\
\hline $\begin{array}{l}\text { Nilai Rerata } \\
\text { Keseluruhan Dimensi } \\
\text { Mutu Dabholkar }\end{array}$ & 2,52 & 3,00 & 84,00 & Belum Sesuai \\
\hline
\end{tabular}


dan harapan pasien berdampak pada kepuasan atas pelayanan yang diterima oleh pasien.Oleh sebab itu, semakin baik tingkat kesesuaian antara harapan dan penilaian maka, semakin baik pula kepuasan pasien terhadap pelayanan kesehatan yang diterimanya. Definisi puas menurut Kotler (2003) adalah suatu keadaan yang dirasakan seseorang, menyenangkan atau mengecewakan yang merupakan hasil dari membandingkan penampilan atau outcome produk yang dirasakan dalam hubungannya dengan apa yang diharapkannya (Harijono dan Kusumapradja, 2003).

Pada tabel 3 dijelaskan bahwa terdapat dua dimensi yang belum memiliki kesesuaian antara penilaian dan harapannya.Kedua dimensi tersebut adalah dimensi aspek fisik dan dimensi kebijakan. Meskipun hanya terdapat dua dimensi dari lima dimensi yang memiliki ketidaksesuaian antara penilaian dan harapan akan tetapi kedua dimensi tersebut harus menjadi fokus utama untuk dilaksanakannya upaya perbaikan dan peningkatan. Sebab, ketidaksesuaian yang terjadi pada kedua dimensi tersebut berpengaruh cukup besar dalam tingkat kesesuaian keseluruhan terhadap pelayanan yang diberikan di Poli Gigi dan Mulut.

Menurut Supriyanto dan Wulandari (2011), ketidaksesuaian ini dapat terjadi bila pemberi layanan langsung belum berfokus pada pelanggan, sehingga salah dalam mempersepsikan kebutuhan dan harapan pelanggan.Faktor penyebab lainnya menurut Tjiptono (2004) sebagai berikut, kurangnya komitmen manajemen pada kualitas pelayanan, persepsi ketidakmampuan manajemen, kurangnya penetapan standar, dan tidak adanya penetapan tujuan.

Berdasarkan hasil perhitungan tingkat kesesuaian antara penilaian dengan harapan responden dilakukan analisis tingkat kesesuaian menggunakan spider web.Analisis menggunakan spider web diperlukan untuk melihat gambaran secara nyata perbedaan atau tingkat kesesuaian antara penilaian dan harapan dari masing-masing dimensi (aspek fisik, reliabilitas, interaksi personal, pemecahan masalah dan kebijakan).Berikut merupakan hasil analisis tingkat kesesuaian antara harapan dengan penilaian menggunakan spider web.

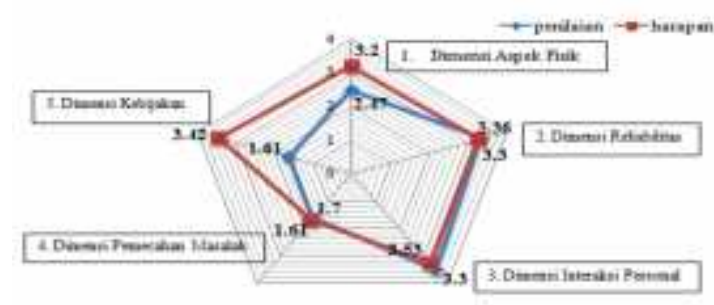

Gambar 1.Spider Web

Berdasarkan Gambar 1 diketahui bahwa tiga dari lima dimensi memiliki tingkat kesesuaian yang baik hingga sangat baik. Akan tetapi tingkat kesesuaian antara penilaian dan harapan secara keseluruhan tergolong belum sesuai.Gap yang terjadi ini memunculkan fenomena yang cukup menarik. Fenomena yang muncul adalah lebih banyak dimensi yang memiliki kesesuaian yang baik antara penilaian dan harapannya akan tetapi tingkat kesesuaian secara keseluruhan tergolong masih belum sesuai antara harapan dengan penilaian responden.

Hal tersebut dapat terjadi karena beberapa faktor, salah satunya adalah pada dimensi kebijakan 
terjadi gap yang cukup besar terkait rerata penilaian dan harapan responden. Selain itu, pada dimensi aspek fisik penilaiannya baik akan tetapi masih belum sesuai atau belum memenuhi harapan responden sehingga menyebabkan tingkat kesesuaiannya tergolong belum sesuai.

Dimensi aspek fisik dan dimensi kebijakan adalah dua dari lima dimensi yang belum sesuai antara penilaian dengan harapan pasien. Dimensi kebijakan memiliki gap yang cukup besar antara penilaian dan harapannya dibandingkan dengan gap yang dimiliki oleh dimensi aspek fisik.Akan tetapi, kedua dimensi tersebut merupakan prioritas utama yang harus dilakukan upaya perbaikan dan peningkatannya agar tercapai kesesuaian yang baik antara penilaian dan harapan pasien terhadap kedua dimensi tersebut.

Pada dimensi aspek fisik salah satu penyebab utama terjadinya ketidaksesuaian penilaian dan harapan responden adalah adanya kerusakan pada salah satu dental chairdi Poli Gigi dan Mulut yang menyebabkan lambatnya pelayanan yang diberikan oleh Poli Gigi dan Mulut. Selain itu, jam buka pelayanan di Poli Gigi dan Mulut yang terbatas menyebabkan Poli Gigi dan Mulut tidak bisa melayani pasien dalam jumlah yang besar setiap harinya.Sedangkan pada dimensi kebijakan, penyebab utama terjadinya ketidaksesuaian penilaian dan harapan responden adalah tidak ada standar operasional prosedur (SOP), tata tertib, hak dan kewajiban pasien serta hak dan kewajiban petugas yang seharusnya terpajang di dalam ruangan Poli Gigi dan Mulut. Keempat macam kebijakan tersebut sangat penting untuk membuat pihak provider dan pihak pasien memiliki satu persepsi yang sama mengenai pelayanan kesehatan yang sesuai standar.

Belum tercapainya kesesuaian yang baik antara penilaian dan harapan pada dimensi aspek fisik dan dimensi kebijakan terhadap pelayanan kesehatan yang diberikan oleh Poli Gigi dan Mulut akan berdampak pada kepuasan dan loyalitas pasien. Kepuasan pasien merupakan salah satu indikator kualitas pelayanan kesehatan yang rumah sakit berikan dan kepuasan pasien adalah salah satu modal untuk mendapatkan pasien lebih banyak lagi dan untuk mendapatkan pasien yang loyal (Supriyanto, 2002).

Penyusunan Rekomendasi Peningkatan Pemanfaatan Pelayanan Kesehatan di Poli Gigi dan Mulut Berdasarkan Dimensi Mutu Dabholkar

Prioritas utama yang menjadi isu pelaksanaan upaya peningkatan pemanfaatan pelayanan kesehatan di Poli Gigi dan Mulut berdasarkan dimensi mutu Dabholkar adalah aspekaspek yang terdapat dalam dimensi aspek fisik dan dimensi kebijakan.

Dalam dimensi aspek fisik aspek-aspek yang menjadi prioritas utama antara lain, penambahan dental chair,penambahan peralatan medis, pembaharuan dental chairsecara berkala,pembaharuan peralatan medis secara berkala,kebersihan ruangan Poli Gigi dan Mulut lebih ditingkatkan, penataan ruangan Poli Gigi dan Mulut lebih teratur,diberi tanaman untuk menambah kenyamanan pada ruang tunggu Instalasi Rawat Jalan (IRJ),kebersihan ruangan lebih ditingkatkan pada ruang tunggu Instalasi Rawat Jalan (IRJ), dan 
penataan ruangan lebih teratur pada ruang tunggu Instalasi Rawat Jalan (IRJ).

Dalam dimensi kebijakan aspek-aspek yang menjadi prioritas utama antara lain, pihak Poli Gigi dan Mulut memasang SOP, tata tertib, hak dan kewajiban pasien serta hak dan kewajiban petugas di ruang poli gigi dan mulut agar petugas yang berada di poli gigi dan mulut senantiasa dapat melakukan pemeriksaan sesuai dengan standar yang berlaku sehingga pemeriksaan yang dilakukan selalu sesuai dengan standar sehingga kualitas pelayanan yang diberikan lebih optimal.

\section{SIMPULAN}

Dimensi aspek fisik dan dimensi kebijakan merupakan prioritas utama yang harus segera dilaksanakan perbaikan dan peningkatan mutu karena dianggap penting oleh pasien namun belum dipenuhi oleh rumah sakit.Berikut merupakan rekomendasi yang disarankan sesuai dengan dua dimensi yang menjadi prioritas utama. Rekomendasi digunakan sebagai bahan masukan untuk upaya peningkatan pemanfaatan pelayanan kesehatan di Poli Gigi dan Mulut.Terkait dengan dimensi aspek fisik rekomendasinya adalah pihak Poli Gigi dan Mulut melakukan komunikasi dan advokasi terhadap pihak rumah sakit untuk mengalokasikan anggaran alat medis khususnya dental chair, peralatan medis, dan pembaharuan secara berkala agar pelayanan yang diberikan dapat lebih optimal, pihak rumah sakit melakukan penataan ulang ruangan Poli Gigi dan Mulut sehingga terlihat lebih rapi dan tertata, pihak rumah sakit melakukan penambahan jumlah jam dinding dan penambahan 1 unit kipas angin atau lebih untuk diletakkan di ruang tunggu Instalasi Rawat Jalan (IRJ) karena apabila diberikan AC kurang efisien karena ruang tunggu adalah ruangan terbuka, pihak rumah sakit melakukan pemantauan terhadap kinerja petugas cleaning service yang bertanggungjawab terhadap kebersihan ruang tunggu Instalasi Rawat Jalan (IRJ) setiap harinya agar petugas lebih memaksimalkan jam kerja yang dimiliki.Terkait dengan dimensi kebijakan rekomendasinya adalah pihak Poli Gigi dan Mulut memasang SOP, tata tertib, hak dan kewajiban petugas serta hak dan kewajiban pasien di ruang poli gigi dan mulut agar petugas yang berada di poli gigi dan mulut senantiasa dapat melakukan pemeriksaan sesuai dengan standar yang berlaku sehingga pemeriksaan yang dilakukan selalu sesuai dengan standar sehingga kualitas pelayanan yang diberikan lebih optimal.

\section{DAFTAR PUSTAKA}

Berry, Parasuraman and Zeithaml. 1993. Ten Lessons for Improving Service Quality. Marketing Science Institute. May, pp. 93-104.

Dabholkar, P.A., Thorpe, D.I., and Dentz, J.O. 1996. A Measure of Service Quality for Retail Stores: Scale Development and Validation.Journal of Academy of Marketing Science. 24(1), pp. 3-16.

Fernandez, Z.E. 2006.Upaya peningkatan pemanfaatan rawat inap di puskesmas berdasarkan analisis penilaian dan harapan masyarakat (studi kasus di Puskesmas manufuri Kabupaten Timor Tengah Utara Propinsi NTT).Tesis. Surabaya. Universitas Airlangga.

Harijono Liman,and Rokiah Kusumapraja. 2003. Upaya Peningkatan Mutu Pelayanan di IGD RS.Sumber Waras Melalui Survei Tingkat Kepuasan Pasien/Keluarganya. Jurnal Manajemen \& Administrasi Rumah Sakit Indonesia Vol. IV No. 4

Parasuraman, A, Zeithaml V.A. and A. Berry L.L. 1998.SERVEQUAL : A. Multiple-item Scale for Measuring Consumer Perseption of Service Quality. Journal of Retailing, Vol. 64 (January), p. 12-35.

Permatasari, Mustika Dyah. 2015. Upaya Peningkatan Pemanfaatan Pelayanan 
Kesehatan di Poli Gigi dan Mulut RSUD Dr. Soegiri Lamongan Berdasarkan Dimensi Mutu Dabholkar.Skripsi. Surabaya. Universitas Airlangga.

Kotler, Philip. 2003. Marketing Management. 11stedition. Prentice Hall, New Jersey

Supriyanto, Stefanus. 2002. Strategi pemasaran jasa pelayanan kesehatan.Surabaya:Airlangga University Press.
Thompson, Andrew G.H., and Sunol, Rosa. 1995. Expectations As a Determinants of Patient Satisfaction: Concept, Theory and Evidence. International Journal for Quality in Health Care. 7(2), pp. 127-144.

Tjiptono, F. 2004. Service, quality, dan satisfaction. Yogyakarta: Penerbit Andi.

Yohanna, Antin. 2009. Analisis Harapan dan Kepuasan Pasien Rawat Inap Penyakit Dalam Terhadap Mutu Pelayanan Dokter Spesialis Di RSI Sunan Kudus.Skripsi. Semarang. Universitas Diponegoro. 